\title{
Chronic relapsing purpura fulminans
}

Biplab Maji ${ }^{1}$, Priyankar Pal $^{2}$, Apurba Ghosh ${ }^{3}$

Sri Lanka Journal of Child Health, 2013; 43(3): 180-181

(Key words: Chronic relapsing purpura fulminans; child)

\section{Introduction}

Purpura fulminans (PF) is the skin manifestation of an acute, often lethal syndrome of disseminated intravascular coagulation (DIC) with rapidly progressive haemorrhagic necrosis of the skin due to dermal vascular thrombosis. PF can be seen in the newborn period as a manifestation of homozygous protein $\mathrm{C}$ deficiency, or rarely protein $\mathrm{S}$ deficiency ${ }^{1}$ or in individuals with acute, severe viral or bacterial infection where an acquired deficiency in protein $\mathrm{C}$ activity is documented ${ }^{2}$.

\section{Case report}

A full term Indian boy was born of a nonconsanguineous marriage after an uneventful pregnancy and uncomplicated delivery. $\mathrm{He}$ received $1 \mathrm{mg}$ of Vitamin $\mathrm{K}$ intramuscularly at birth, and developed ecchymotic lesions over the tip of the fingers of right hand and lateral side of the right thigh. Within a few hours the ecchymotic lesions enlarged in size and converted into painful haematomas. In the absence of any clinical or laboratory evidence of infection and undetectable level of protein $\mathrm{C}$ in the serum of the baby, it was diagnosed as a case of homozygous protein $\mathrm{C}$ deficiency as both parents had heterozygous protein $\mathrm{C}$ deficiency.

In spite of fresh frozen plasma transfusion within 8 hours of onset of purpura fulminans and protein $\mathrm{C}$ transfusion on 4th day of life, we were unable to prevent the amputation of right middle finger and a large skin necrosis on the thigh (Figures $1 \& 2$ ).

Then onwards the patient had recurrent attacks of purpura fulminans, even on oral warfarin therapy, probably because of poor compliance. The possibility of warfarin induced skin necrosis was excluded by repeated assessment of the protein $\mathrm{C}$ antigen level.

${ }^{1}$ Post Graduate Trainee, MD, Paediatrics,

${ }^{2}$ Associate Professor, ${ }^{3}$ Professor and Director, Institute Of Child Health,11 Biresh Guha Road, Kolkata 700017, India

(Received on 14 September 2013: Accepted after revision on 25 October 2013)

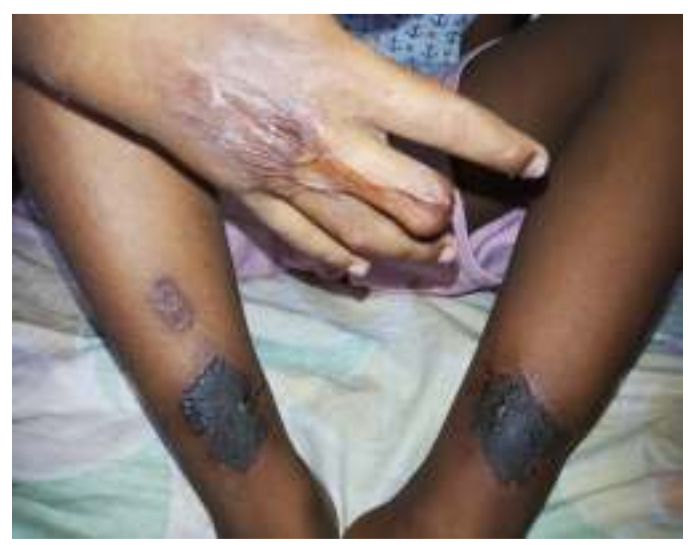

Figure 1: Amputation of right middle finger

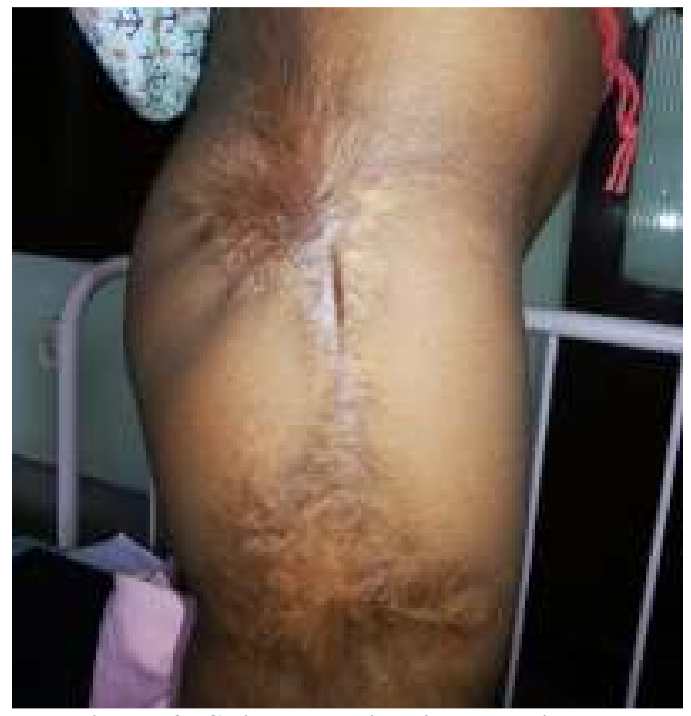

Figure 2: Skin necrosis with scarring

\section{Discussion}

At the onset of symptoms, the initial treatment should be plasma ( 8 to $12 \mathrm{ml} / \mathrm{kg}$ every 12 hours) until all lesions have healed, followed by oral anticoagulant therapy ${ }^{3}$ or protein $\mathrm{C}$ replacement ${ }^{4}$ (fresh frozen plasma or prothrombin complex concentrate). Liver transplantation is the definitive treatment. Oral anticoagulation (vitamin K antagonists, maintaining the international Normalized Ratio of 2.5 to 4.4) is the recommendation of choice for long-term treatment. 


\section{References}

1. Meningococcal sepsis and purpura fulminans: the surgical perspective. Postgraduate Medical Journal 2013; 89(1052): 340-5.

http://dx.doi.org/10.1136/postgradmedj-2012$\underline{130989}$

2. Varicella purpura fulminans associated with heterozygosity for Factor V Leiden and transient protein $\mathrm{S}$ deficiency. Pediatrics 1998; 102(5): 1208-10. http://dx.doi.org/10.1542/peds.102.5.1208
3. Emerging anticoagulant drugs. Arteriosclerosis, Thrombosis \& Vascular Biology 2003; 23:1491-1500.

http://dx.doi.org/10.1161/01.ATV.0000084827 .77945 .66

4. Engineering the proteolytic specificity of activated protein $\mathrm{C}$ improves its pharmacological properties. Proceedings of the National Academy of Sciences USA 2003; 100:4423-8.

http://dx.doi.org/10.1073/pnas.0736918100 